\title{
Article \\ Adsorptive Removal of Arsenic and Lead by Stone Powder/Chitosan/Maghemite Composite Beads
}

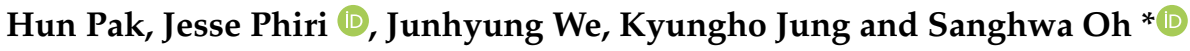 \\ School of Architectural, Civil, Environmental, and Energy Engineering, Kyungpook National University, \\ Daegu 41566, Korea; ph6524@knu.ac.kr (H.P.); jesset.phiri@knu.ac.kr (J.P.); gud6417@knu.ac.kr (J.W.); \\ nabi6030@daum.net (K.J.) \\ * Correspondence: shoh@knu.ac.kr
}

Citation: Pak, H.; Phiri, J.; We, J.; Jung, K.; Oh, S. Adsorptive Removal of Arsenic and Lead by Stone Powder/Chitosan/Maghemite Composite Beads. Int. J. Environ. Res. Public Health 2021, 18, 8808. https:// doi.org/10.3390/ijerph18168808

Academic Editors: Cristina Pignata and Paul B. Tchounwou

Received: 12 July 2021

Accepted: 18 August 2021

Published: 20 August 2021

Publisher's Note: MDPI stays neutral with regard to jurisdictional claims in published maps and institutional affiliations.

Copyright: (c) 2021 by the authors. Licensee MDPI, Basel, Switzerland. This article is an open access article distributed under the terms and conditions of the Creative Commons Attribution (CC BY) license (https:// creativecommons.org/licenses/by/ $4.0 /)$.

\begin{abstract}
Arsenic (As) and lead $(\mathrm{Pb})$ contamination in groundwater is a serious problem in countries that use groundwater as drinking water. In this study, composite beads, called SCM beads, synthesized using stone powder (SP), chitosan (Ch), and maghemite (Mag) with different weight ratios $(1 / 1 / 0.1,1 / 1 / 0.3$, and 1/1/0.5 for SP/Ch/Mag) were prepared, characterized and used as adsorbents for the removal of $\mathrm{As}$ and $\mathrm{Pb}$ from artificially contaminated water samples. Adsorption isotherm experiments of $\mathrm{As}$ and $\mathrm{Pb}$ onto the beads were conducted and single-solute adsorption isotherm models such as the Langmuir, Freundlich, Dubinin-Radushkevich (DR), and dual mode (DM) models were fitted to the experimental data to analyze the adsorption characteristics. The maximum adsorption capacities of the SCM beads were 75.7 and $232.8 \mathrm{mmol} / \mathrm{kg}$ for As and $\mathrm{Pb}$, respectively, which were 40 and 5.6 times higher than that of SP according to the Langmuir model analyses. However, the DM model had the highest determinant coefficient $\left(R^{2}\right)$ values for both As and $\mathrm{Pb}$ adsorption, indicating that the beads had heterogenous adsorption sites with different adsorption affinities. These magnetic beads could be utilized to treat contaminated groundwater.
\end{abstract}

Keywords: arsenic; lead; maghemite; chitosan; stone powder; bead; adsorption

\section{Introduction}

Groundwater contamination has become a serious environmental concern throughout the world. In several countries such as Bangladesh, Vietnam, Pakistan, and China as well as the USA, Hungary, and Mexico, many people are exposed to high levels of arsenic (As) and/or lead $(\mathrm{Pb})$ via the intake of contaminated groundwater [1-5]. As and $\mathrm{Pb}$ are considered to be the most hazardous chemicals in the world, and the excessive and longterm intake of these chemicals causes several serious health problems, including suffering from incurable diseases, such as cancer, and potentially causing death [6]. In particular, the high As concentration in the groundwater in southeastern Asian countries poses a serious threat to the lives of many people.

Various technologies for $\mathrm{As}$ and $\mathrm{Pb}$ removal from contaminated water have been developed, including adsorption, ion exchange, $\mathrm{pH}$ control, and precipitation [7,8]. Adsorption is considered to be one of the more attractive technologies, and various adsorbents that are effective in $\mathrm{As}$ and $\mathrm{Pb}$ removal have been developed. For As removal, iron-based compounds such as goethite [9-11], hematite [11,12], magnetite [11,12], maghemite [12,13], ferrihydrite [12,14], zero valent iron [11,12,15,16], amorphous hydrous ferric oxides [16,17], iron-coated materials [12,18], and mackinawite [19], have been considered as preferred adsorbents because iron oxides are abundant in nature. For Pb removal, soils [20-23], zeolite [24], carbon aerogel [25], and metal oxides, such as iron oxides [26-28] and aluminum oxides [29], have been studied.

Iron oxides have excellent adsorption capacities for As and $\mathrm{Pb}$. Ghosh et al. [9] reported that goethite nanoparticles have a high As adsorption capacity $(76 \mathrm{mg} / \mathrm{g})$. Tuutijarvi et al. [13] reported that maghemite nanoparticles adsorb high amounts of As (50 mg/g). 
However, because iron oxide usually exists as a fine powder, it is difficult to apply in field treatments [30]. Therefore, to improve its field applicability, magnetic (nano) particles synthesized from iron oxide were researched and developed by several groups [31-34]. For example, Cho et al. [31] synthesized a chitosan/clay $/ \mathrm{Fe}_{3} \mathrm{O}_{4}$ composite material to remove cationic and anionic dyes. Podder and Majumder [32] applied a granular activated carbon $/ \mathrm{MnFe}_{2} \mathrm{O}_{4}$ composite to remove As. In addition, many studies have used chitosan as a cross-linker for the synthesis of composite beads, which can bridge and aggregate chitosan, iron-oxide and other powders [31,33,34]. Adsorbents with magnetic beads with biopolymers are attractive because of their adsorption efficiency and magnetic properties [34].

Chitosan-based adsorbents are interesting because of their eco-friendly properties [31]. Because chitosan contains hydroxyl $(-\mathrm{OH})$ and amino $\left(-\mathrm{NH}_{2}\right)$ groups, it has a problem with liquidation in which its structure collapses under acidic conditions. A cross-linking agent, such as triphosphate (TPP), can be used to prevent liquidation [35]. Cho et al. [31] and Ngah and Fatinathan [36] reported that TPP bridges chitosan polymers with protonated amines and encapsulates it into a bead form. For example, Cho et al. [31] synthesized a chitosan/clay $/ \mathrm{Fe}_{3} \mathrm{O}_{4}(\mathrm{CCM})$ composite in which chitosan acts as a cross-linker between the clay and the $\mathrm{Fe}_{3} \mathrm{O}_{4}$ and the clay acts as a frame structure. In this study, stone powder (SP) was used to act as a frame structure instead of clay. Untreated SP waste can cause environmental pollution in soil, surface water, and groundwater. Only a small portion of $\mathrm{SP}$ is recycled for construction purposes [37] but it is not used for environmental purposes because of its poor manageability.

This study, accordingly, synthesizes a bead containing maghemite, chitosan, and SP for the adsorption of $\mathrm{As}$ and $\mathrm{Pb}$ and evaluates the performance of the composite bead adsorbent and the factors affecting adsorption, for example, the maghemite/SP weight ratio, bead dose, and temperature. Several adsorption isotherm models, i.e., the Langmuir, Freundlich, Dubnin-Radushkevich (D-R), and dual-mode (DM) models were used to fit the adsorption data.

\section{Materials and Methods}

\subsection{Materials}

SP was obtained from a masonry mill in Yeongcheon, Korea, air-dried, sieved using a $75 \mu \mathrm{m}$ mesh (sieve \#200), and stored in an airtight plastic bottle before use [38]. Chitosan $\left(\left(\mathrm{C}_{6} \mathrm{H}_{11} \mathrm{NO}_{4}\right)_{\mathrm{n}}\right.$ with $75-85 \%$ degree deacetylation and a viscosity $(0.5 \%)$ of $\left.5-20 \mathrm{mPa} \cdot \mathrm{s}\right)$ was purchased from Showa, Japan. Sodium arsenate dibasic heptahydrate $\left(\mathrm{Na}_{2} \mathrm{HAsO}_{4}\right.$, $>99.0 \%)$ was purchased from Wako, Japan. Lead nitrate $\left(\mathrm{Pb}\left(\mathrm{NO}_{3}\right)_{2},>99.0 \%\right)$, acetic acid $\left(\mathrm{CH}_{3} \mathrm{COOH},>98.0 \%\right)$, iron(II) chloride $\left(\mathrm{FeCl}_{2},>99.0 \%\right)$, iron(III) chloride anhydrous $\left(\mathrm{FeCl}_{3}\right.$, $>98.0 \%)$, and hydrochloric acid $(\mathrm{HCl}, 35-37 \%)$ were purchased from Duksan Co., Ansan, Korea. MES (2-( $\mathrm{N}$-morpholino)ethanesulfonic acid, $>98.0 \%)$, sodium tripolyphosphate (STPP, $\left.\mathrm{NaP}_{3} \mathrm{O}_{10},>99.0 \%\right)$, and sodium bicarbonate $\left(\mathrm{NaHCO}_{3},>99.0 \%\right)$ were purchased from Daejung Chem. \& Metals Co., Siheung, Korea. Iron(III) nitrate $\left(\mathrm{Fe}\left(\mathrm{NO}_{3}\right)_{3} 9 \mathrm{H}_{2} \mathrm{O}\right.$, $>98.0 \%$ ) was purchased from OCI Co., Seoul, Korea.

\subsection{Ferrofluid Synthesis}

A ferrofluid composed of maghemite $\left(\gamma-\mathrm{Fe}_{2} \mathrm{O}_{3}\right)$ was synthesized according to the modification of the Massart method [39]. In brief, a $0.7 \mathrm{M}$ ammonia solution $\left(\mathrm{NH}_{4} \mathrm{OH}\right)$ was added to a mixture of iron(III) chloride $(40 \mathrm{~mL}, 1 \mathrm{M})$ and iron(II) chloride $(10 \mathrm{~mL}, 2 \mathrm{M})$ to form black-colored settled particles. The particles were separated via centrifugation at $1500 \mathrm{rpm}$ for $10 \mathrm{~min}$, dispersed into a $0.34 \mathrm{M}$ nitrate solution with a $\mathrm{pH}$ of 2, and then oxidized to maghemite with iron(III) nitrate at $90^{\circ} \mathrm{C}$ for over $1 \mathrm{~h}$. The synthesized maghemite concentration in the ferrofluids was approximately $10 \mathrm{~g} / \mathrm{L}$ as solids. 


\subsection{SP/Chitosan/Maghemite Bead Synthesis}

The synthesis protocol for the SP/chitosan/maghemite (SCM) beads was based on the protocol of Bee et al. [34]. Briefly, $2 \mathrm{~g}$ of chitosan was dissolved in $100 \mathrm{~mL}$ of $2 \%$ acetic acid. Then, $2 \mathrm{~g}$ of SP and an appropriate amount of ferrofluid solution corresponding to the different weights of $0.2,0.67$, or $1.0 \mathrm{~g}$ of maghemite were added to the chitosan solution. The solution was then mixed at approximately $50{ }^{\circ} \mathrm{C}$ until the viscosity of the mixed solution reached approximately $25-28 \mathrm{mPa} \cdot \mathrm{s}$. In addition, $500 \mathrm{~mL}$ of $0.5 \mathrm{M}$ sodium triphosphate (STPP) was prepared in a $1 \mathrm{~L}$ beaker. The SCM mixture solution was transferred into a $50 \mathrm{~mL}$ syringe installed on a syringe pump and then added dropwise to the STPP solution to form beads. The beads were cured for approximately $24 \mathrm{~h}$, washed twice with ultrapure water, and then dried at $50{ }^{\circ} \mathrm{C}$ in an oven for $24 \mathrm{~h}$. The synthesized beads had three weight ratios of SP, chitosan, and maghemite: $1 / 1 / 0.1,1 / 1 / 0.3$, and 1/1/0.5.

\subsection{Characterization of the SCM Beads}

The surface shape of the SCM beads was observed using a microscope (Zeiss, Axioplan 2 Imaging, Axiovert 200, Jena, Germany). A field emission scanning electron microscope (FE-SEM, SU8220, Hitachi, Japan) was used to observe the SCM morphology and an energy dispersive X-ray spectroscope (EDS, Horiba E-MAX EDS detector, Kyoto, Japan) was used to characterize the chemical compositions. Fourier transform infrared spectroscopy (FT-IR) was used for the characterization of the bead structural features. The surface area and pore size of the SCM beads were measured using the Brunauer-Emmett-Teller (BET) method (BET Quantachrome, Autosorb-iQ, Boynton Beach, FL, USA) via the $\mathrm{N}_{2}$ adsorption isotherm. The BET, microscope, and FE-SEM/EDS analyses were conducted at the Instrumental Analysis Center of Kyungpook National University, Korea.

\subsection{Adsorption Isotherm Experiments}

Isothermal adsorption tests were performed to evaluate the adsorption capacity of the $\mathrm{SCM}$ beads and $\mathrm{SP}$ to As and $\mathrm{Pb}$. All experiments were performed in a $50 \mathrm{~mL}$ centrifuge tube (PE, SPL Pocheon, Korea). A total of $0.5 \mathrm{~g}$ of SCM beads or $1.0 \mathrm{~g}$ of SP powder was prepared in screw-cap conical tubes with an available volume of $50 \mathrm{~mL}$, and then metal solutions (As: $0.013-1.33 \mathrm{mmol} / \mathrm{L}$ or $\mathrm{Pb}: 0.965-9.65 \mathrm{mmol} / \mathrm{L}$ ) with a background electrolyte of $0.01 \mathrm{M} \mathrm{NaNO}_{3}$ were added. The tubes were capped tightly and shaken at $200 \mathrm{rpm}$ for $24 \mathrm{~h}$ in an orbital shaker. After mixing, all tubes were centrifuged at $2000 \mathrm{rpm}$ for $10 \mathrm{~min}$. The supernatant was filtrated through a $0.2 \mu \mathrm{m}$ membrane filter (cellulose nitrate membrane, Whatman). The $\mathrm{As}$ and $\mathrm{Pb}$ concentrations in the aqueous phases were analyzed using an inductively coupled plasma (ICP, Optima 2100 DV, PerkinElmer, Hägersten, Sweden). The $\mathrm{pH}$ of the electrolyte solution was in the range of $4-5$ adjusted with $0.1 \mathrm{~N}$ $\mathrm{HCl}$ and $0.1 \mathrm{~N} \mathrm{NaOH}$. All experiments were conducted in duplicate.

The solid phase adsorbed amount, $q(\mathrm{mmol} / \mathrm{kg})$, was calculated using Equation (1):

$$
q=\frac{\left(C_{0}-C\right) V}{W}
$$

where $C_{0}$ is the initial solute concentration $(\mathrm{mmol} / \mathrm{L}), C$ is the residual solute concentration $(\mathrm{mmol} / \mathrm{L}), V$ is the sample volume $(\mathrm{L})$, and $W$ is the weight of the adsorbent SCM $\left(\times 10^{-3} \mathrm{~kg}\right)$.

\section{Results}

\subsection{SCM Characteristics}

The specific area, pore volume, pore size, and $\mathrm{pH}$ values of the SCM beads and SP are summarized in Table 1. Because the SP used in this study is the same as that used in the previous study [36], the SP properties were also the same. The surface area of the SCM beads was $0.543-0.834 \mathrm{~m}^{2} / \mathrm{g}$, which was approximately a quarter of that of $\mathrm{SP}\left(2.782 \mathrm{~m}^{2} / \mathrm{g}\right)$. The pore volume of the beads was in the range of $0.0027-0.0047 \mathrm{~cm}^{3} / \mathrm{g}$ which was lower 
than that of SP, whereas the pore size of the beads $(20.0-27.9 \mathrm{~nm})$ was similar to that of SP $(24.8 \mathrm{~nm})$.

Table 1. Properties of the SP/chitosan/maghemite (SCM) beads and SP.

\begin{tabular}{ccccc}
\hline & \multicolumn{3}{c}{ SCMs } & SP [37] \\
\cline { 2 - 4 } & $\mathbf{1 / 1 / 0 . 1}$ & $\mathbf{1 / 1 / 0 . 3}$ & $\mathbf{1 / 1 / 0 / 5}$ & \\
\hline $\mathrm{pH}$ & 5.4 & 5.6 & 5.6 & 4.7 \\
BET surface area $\left(\mathrm{m}^{2} / \mathrm{g}\right)$ & 0.543 & 0.570 & 0.834 & 2.782 \\
Pore volume $\left(\mathrm{cm}^{3} / \mathrm{g}\right)$ & 0.00271 & 0.00397 & 0.00467 & 0.017 \\
Pore size $(\mathrm{nm})$ & 19.98 & 27.86 & 22.42 & 24.83 \\
\hline
\end{tabular}

Microscopic images and scanning electron microscopic (SEM) images show the shapes of the SCM beads in Figure 1. As shown in Figure 1a-c, the beads are brownish, have a round shape, and become darker as the maghemite content increases from 0.1 to $0.5 \mathrm{wt} . \%$. The beads are hollow spheres (Figure 1b), and the surface of the beads was pitted as a result of shrinkage during drying as shown in Figure 1d-f (SEM images).
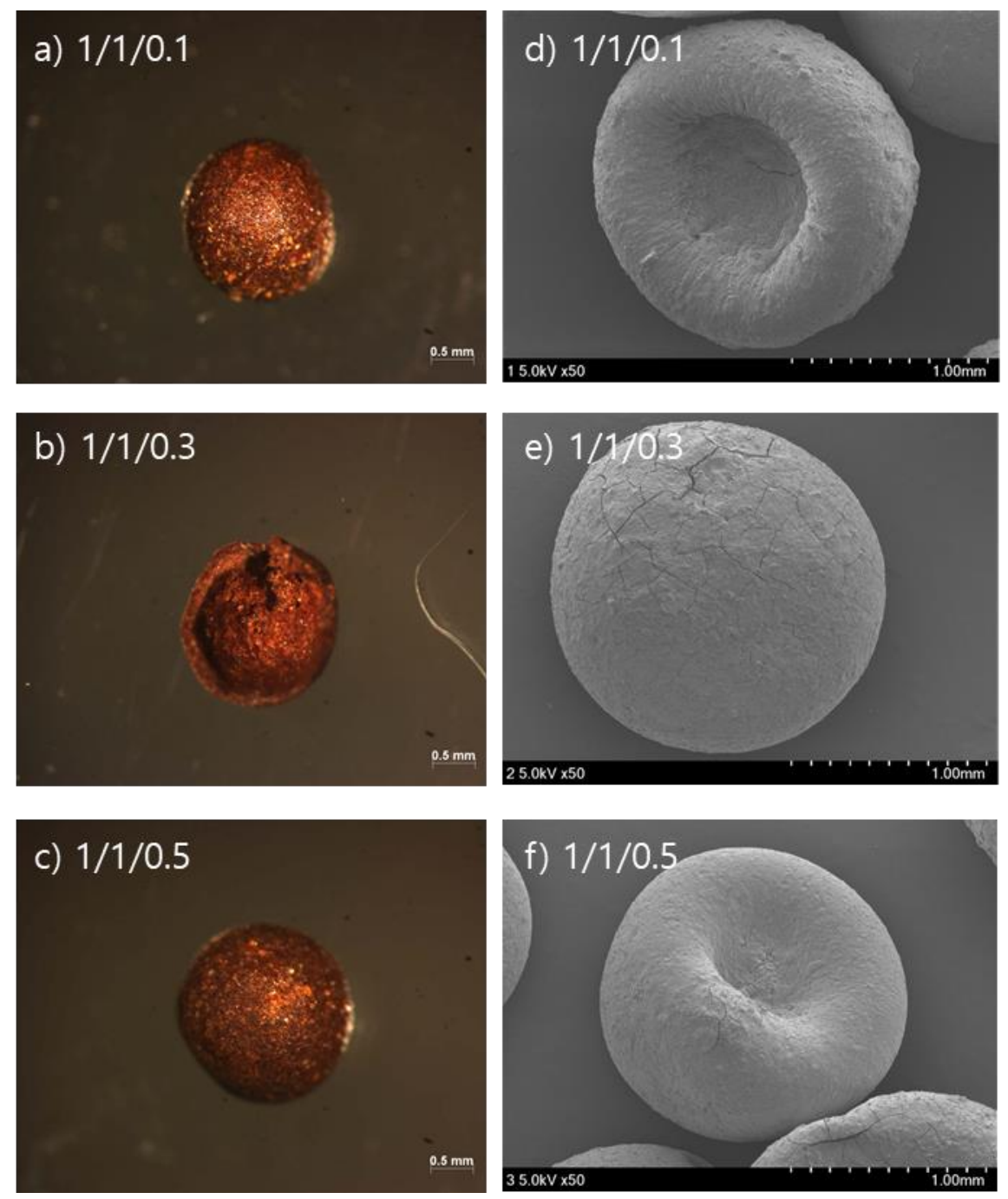

Figure 1. Microscopic (a-c) and SEM images (d-f) of SCM beads.

Figure 2 shows the SEM images and EDS graphs for the beads and SP. Figure 2a-d present the SEM images for the SCM beads $(1 / 1 / 0.1,1 / 1 / 0.3$, and $1 / 1 / 0.5)$ and SP, respectively. The EDS analytic results are summarized in Table 2. As shown in Figure 2, O, C, and P are 
prominent elements for the beads whereas $\mathrm{Si}$ is the largest component of SP. In Table 2, the Fe contents in beads $1 / 1 / 0.1,1 / 1 / 0.3$, and $1 / 1 / 0.5$ are $0.81,2.62$, and $2.89 \%$, respectively, which are higher than the Fe content in SP $(0.23 \%)$. The high Fe content in the beads can provide sufficient adsorption sites as reported by Ghosh et al. [9], i.e., iron-based adsorbents have high arsenic adsorption capacities. As can be seen in Table 2, the Fe content of bead $1 / 1 / 0.5(2.89 \%)$ was lower than expected, and was not significantly different from that of bead 1/1/0.3 (2.62\%). If the adsorption of As is dependent on the Fe content, the two beads would be expected to have similar adsorption capacities.
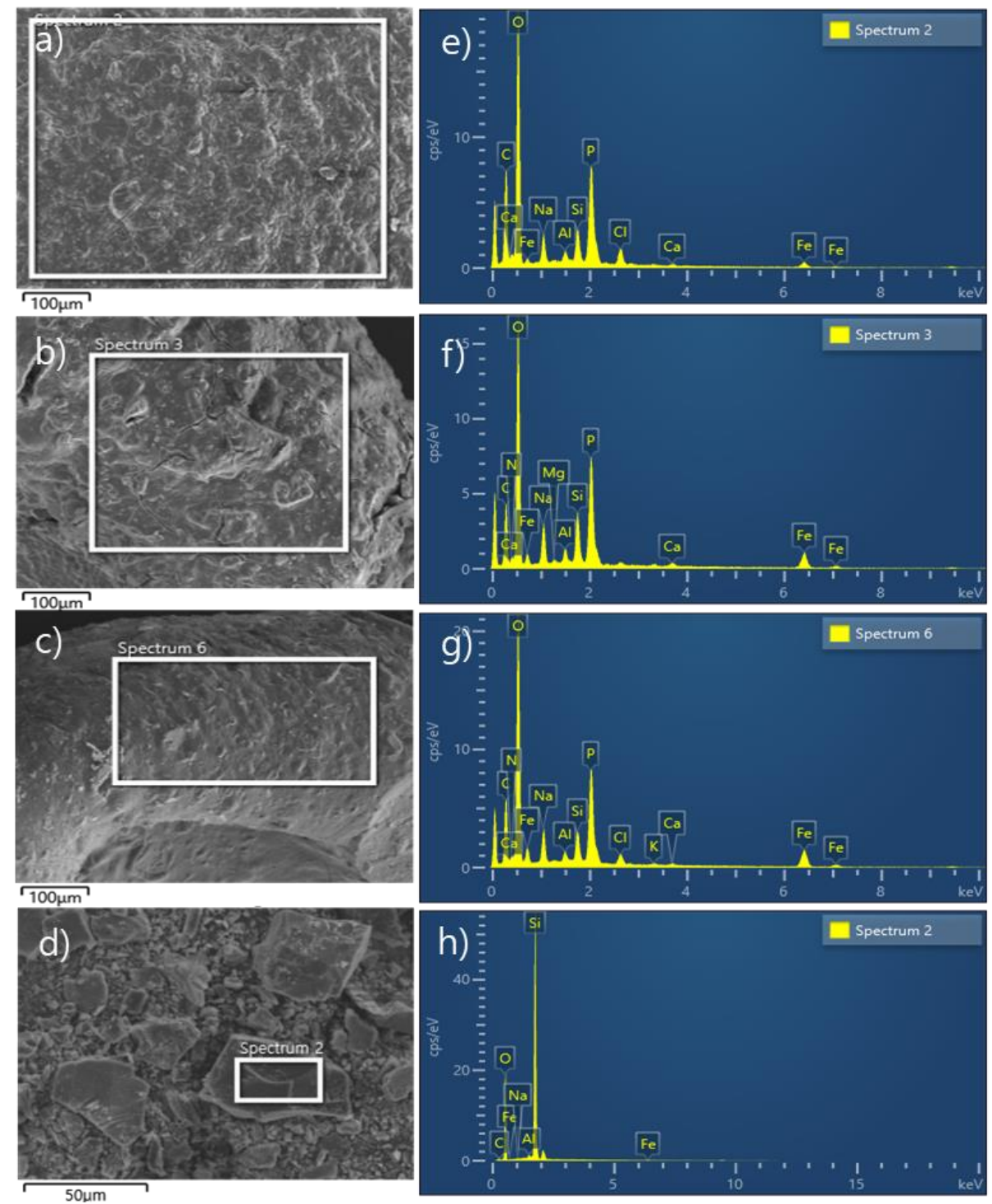

Figure 2. SEM images (a-d) and EDS spectra (e-h) of the SCM beads and SP: (a,e) bead 1/1/0.1; $(\mathbf{b}, \mathbf{f})$ bead $1 / 1 / 0.3 ;(\mathbf{c}, \mathbf{g})$ bead $1 / 1 / 0.5$; and $(\mathbf{d}, \mathbf{h})$ SP. 
Table 2. EDS results for the SCMs and SP.

\begin{tabular}{ccccc}
\hline \multirow{2}{*}{ Element } & \multicolumn{3}{c}{ Atomic \% of SCMs } & Atomic \% of SP \\
\cline { 2 - 4 } & $\mathbf{1 / 1 / 0 . 1}$ & $\mathbf{1 / 1 / 0 . 3}$ & $\mathbf{1 / 1 / 0 / 5}$ & 8.52 \\
$\mathrm{C}$ & 45.34 & 35.47 & 37.56 & - \\
$\mathrm{N}$ & - & 4.39 & 4.88 & 53.88 \\
$\mathrm{O}$ & 45.79 & 46.55 & 45.92 & 0.14 \\
$\mathrm{Na}$ & 1.81 & 3.01 & 2.44 & - \\
$\mathrm{Mg}$ & - & 0.19 & - & 0.36 \\
$\mathrm{Al}$ & 0.39 & 0.61 & 0.41 & 36.88 \\
$\mathrm{Si}$ & 1.28 & 2.17 & 1.28 & - \\
$\mathrm{P}$ & 3.70 & 4.78 & 3.95 & - \\
$\mathrm{Cl}$ & 0.76 & - & 0.50 & - \\
$\mathrm{K}$ & - & - & 0.06 & 0.23 \\
$\mathrm{Ca}$ & 0.12 & 0.20 & 0.11 & \\
$\mathrm{Fe}$ & 0.81 & 2.62 & 2.89 & \\
\hline
\end{tabular}

FT-IR spectra for the bead only, the As adsorbed bead, and the $\mathrm{Pb}$ adsorbed bead are shown in Figure 3. Several bands were observed at 2,150, 1630, 1000, 780, and $580 \mathrm{~cm}^{-1}$ and a wide crest was observed in the region from 3700 to $3000 \mathrm{~cm}^{-1}$ for all beads. In this region, the absorptions were caused by the $\mathrm{N}-\mathrm{H}$ and $\mathrm{O}-\mathrm{H}$ bonds. The bands at 1000 and $780 \mathrm{~cm}^{-1}$ could be attributed to $-\mathrm{C}-\mathrm{O}$ str and $\mathrm{As}-\mathrm{O}-\mathrm{Fe}$ stretching vibrations, respectively.

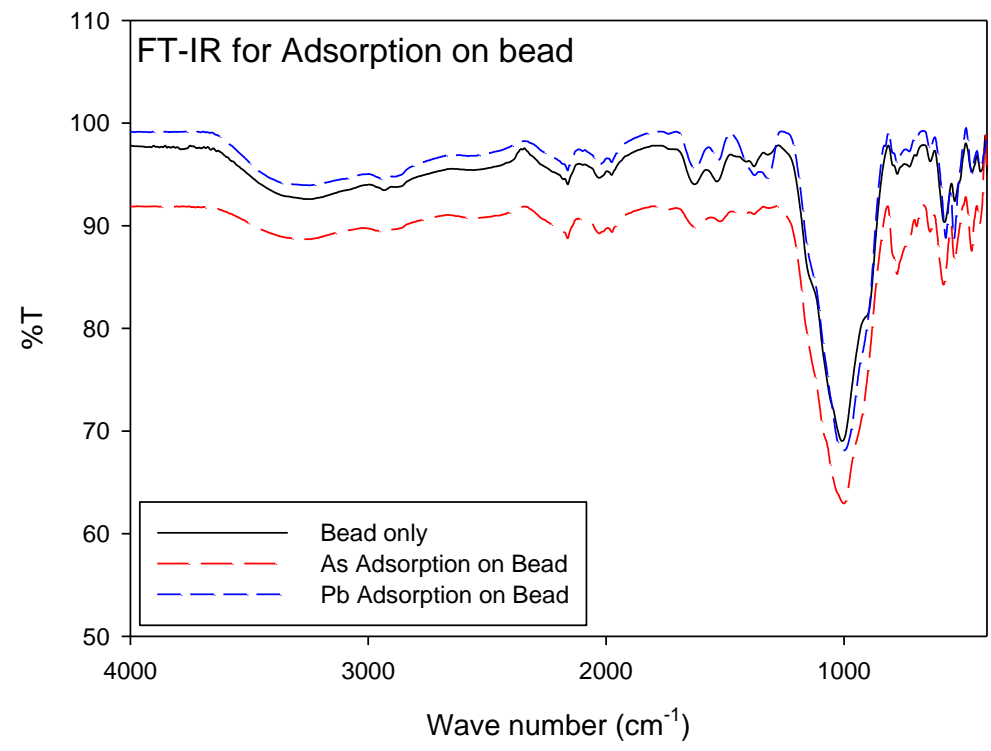

Figure 3. FT-IR spectra of the bead only; the As-loaded bead; and a Pb-loaded bead.

\subsection{Adsorption Characteristics of As onto the Beads}

The experimental results on the adsorption of $\mathrm{As}$ and $\mathrm{Pb}$ onto the beads and $\mathrm{SP}$ are presented here. Based on the data, nonlinear relationships between $C$ and $q$ were observed for all adsorption isotherm experiments. The adsorption isotherms of As onto the SCM beads and SP were studied by fitting the experimental data to the representative isotherm models such as the Langmuir, Freundlich, D-R, and DM models, as shown in Table 3. 
Table 3. Adsorption isotherm models used in this study.

\begin{tabular}{|c|c|c|}
\hline Model & Equation & Fitting Parameters \\
\hline $\begin{array}{l}\text { Langmuir } \\
\text { Freundlich }\end{array}$ & $\begin{array}{c}q=q_{m L} b C /(1+b C) \\
q=K_{F} C^{N}\end{array}$ & $\begin{array}{c}q_{\mathrm{mL}}(\mathrm{mmol} / \mathrm{kg}) \text { and } b(\mathrm{~L} / \mathrm{mmol}) \\
K_{\mathrm{F}}\left[(\mathrm{mmol} / \mathrm{kg}) /(\mathrm{mmol} / \mathrm{L})^{N}\right] \text { and } N(-)\end{array}$ \\
\hline Dubinin-Radushkevich (D-R) [40] & $\begin{array}{c}q=q_{m D} \exp \left(-\beta \varepsilon^{2}\right) \\
=q_{m D} \exp \left[-\beta(R T \ln (1+1 / C))^{2}\right]\end{array}$ & $\begin{array}{c}q_{\mathrm{mD}}(\mathrm{mmol} / \mathrm{kg}) \text { and } \beta\left(\mathrm{mol}^{2} / \mathrm{kJ}^{2}\right) \\
E=1 / \sqrt{2 \beta}\end{array}$ \\
\hline Dual mode (DM) [41] & $q=K_{p D M} C+q_{m D M} b_{D M} C /\left(1+b_{D M} C\right)$ & $\begin{array}{l}K_{\mathrm{pDM}}(\mathrm{L} / \mathrm{kg}), q_{\mathrm{mDM}}(\mathrm{mmol} / \mathrm{kg}) \\
\text { and } b_{\mathrm{DM}}(\mathrm{L} / \mathrm{mmol})\end{array}$ \\
\hline
\end{tabular}

Figure 4 shows the adsorption isotherm of As onto the SCM beads with three different ratios of SP/chitosan/maghemite $(1 / 1 / 0.1,1 / 1 / 0.3$, and $1 / 1 / 0.5)$ compared with that onto SP. As shown in Figure 4 , the As concentration $\left(q_{\mathrm{e}}\right)$ adsorbed onto the beads significantly increased compared with that on SP and increased with the maghemite ratio in the beads $(1 / 1 / 0.5>1 / 1 / 0.3>1 / 1 / 0.1)$. All adsorptions showed a mixed pattern of C- and L-type isotherms.
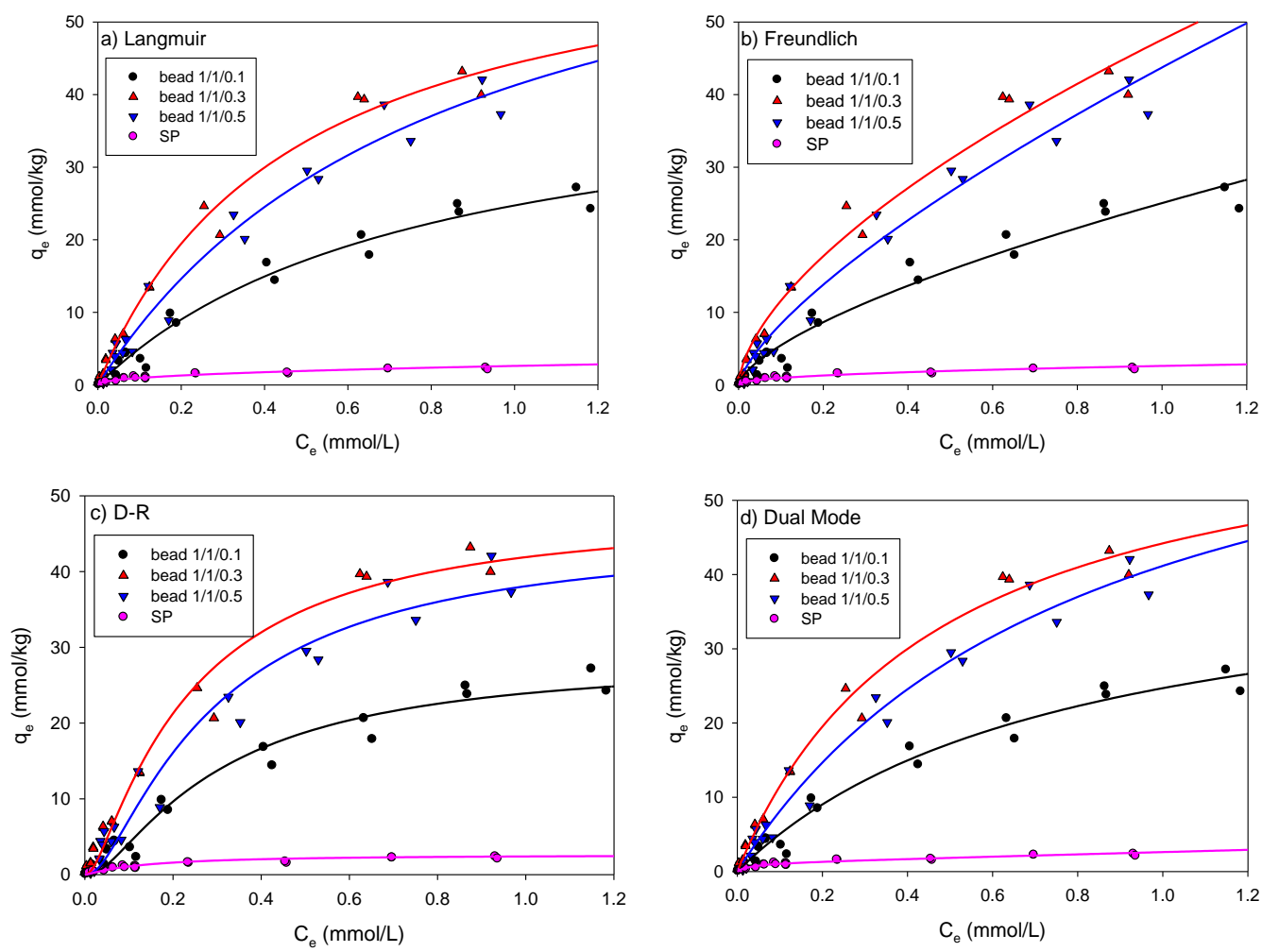

Figure 4. Nonlinear fitting of the (a) Langmuir; (b) Freundlich; (c) D-R; and (d) DM models for As adsorption onto the SCM beads and SP.

Table 4 shows a summary of the fitted model parameters, the determinant coefficients $\left(\mathrm{R}^{2}\right)$, and the squared standard errors (SSE) for As adsorption onto the beads and SP. The $\mathrm{R}^{2}$ values of the As adsorption onto the beads and SP were all higher than 0.90 , indicating that all isotherm models can generate a satisfactory fit to the data. Of the models, the Langmuir and DM models fitted the data more accurately than the others. 
Table 4. Comparison of the isotherm model parameters for As.

\begin{tabular}{|c|c|c|c|c|c|}
\hline \multirow{2}{*}{ Model } & \multirow{2}{*}{ Parameter } & \multicolumn{3}{|c|}{ SCM Bead } & \multirow{2}{*}{ SP } \\
\hline & & 1/1/0.1 & $1 / 1 / 0.3$ & $1 / 1 / 0.5$ & \\
\hline \multirow{5}{*}{ Langmuir } & $q_{\mathrm{mL}}(\mathrm{mmol} / \mathrm{kg})$ & 43.94 & 65.06 & 75.74 & 1.838 \\
\hline & $\mathrm{b}(\mathrm{L} / \mathrm{mmol})$ & 1.288 & 2.134 & 1.196 & 14.45 \\
\hline & $R^{2}$ & 0.977 & 0.988 & 0.977 & 0.900 \\
\hline & SSE & 42.43 & 41.18 & 104.7 & 0.134 \\
\hline & $\mathrm{R}_{\mathrm{L}}$ & 0.017 & 0.007 & 0.011 & 0.036 \\
\hline \multirow{4}{*}{ Freundlich } & $K_{\mathrm{F}}\left(\mathrm{mmol}^{1-N} \mathrm{~L}^{N} / \mathrm{kg}\right)$ & 25.06 & 47.56 & 43.74 & 4.072 \\
\hline & $N(-)$ & 0.662 & 0.613 & 0.717 & 0.572 \\
\hline & $\mathrm{R}^{2}$ & 0.966 & 0.979 & 0.967 & 0.899 \\
\hline & SSE & 63.32 & 86.81 & 145.7 & 0.136 \\
\hline \multirow{5}{*}{ D-R } & $q_{\mathrm{mD}}(\mathrm{mmol} / \mathrm{kg})$ & 28.07 & 47.22 & 44.30 & 1.883 \\
\hline & $\beta\left(\mathrm{mol}^{2} / \mathrm{kJ}^{2}\right), \times 10^{-2}$ & 5.432 & 4.051 & 5.143 & 1.570 \\
\hline & $E(\mathrm{~kJ} / \mathrm{mol})$ & 3.036 & 3.515 & 3.119 & 5.646 \\
\hline & $\mathrm{R}^{2}$ & 0.966 & 0.977 & 0.964 & 0.900 \\
\hline & SSE & 63.29 & 92.33 & 158.9 & 0.134 \\
\hline \multirow{5}{*}{$\mathrm{DM}$} & $K_{\mathrm{pDM}}(\mathrm{L} / \mathrm{kg})$ & 0.037 & 0.037 & 0.049 & 0.001 \\
\hline & $q_{\mathrm{mDM}}(\mathrm{mmol} / \mathrm{kg})$ & 43.49 & 64.62 & 74.90 & 1.834 \\
\hline & $b_{\mathrm{DM}}(\mathrm{L} / \mathrm{mmol})$ & 1.307 & 2.164 & 1.217 & 14.52 \\
\hline & $\mathrm{R}^{2}$ & 0.977 & 0.988 & 0.977 & 0.900 \\
\hline & SSE & 42.46 & 47.21 & 104.7 & 0.134 \\
\hline
\end{tabular}

In the Langmuir model, the maximum adsorption capacity, $q_{\mathrm{mL}}$, increased as the maghemite content increased and there was little difference between the $q_{\mathrm{mL}}$ values for beads $1 / 1 / 0.3$ and $1 / 1 / 0.5$. In the same concentration range, the maximum adsorption capacity increased by 24 times for bead 1/1/0.1 $(43.94 \mathrm{mmol} / \mathrm{kg}), 35$ times for bead $1 / 1 / 0.3(65.06 \mathrm{mmol} / \mathrm{kg})$, and 41 times for bead $1 / 1 / 0.5(75.74 \mathrm{mmol} / \mathrm{kg})$ compared with SP $(1.84 \mathrm{mmol} / \mathrm{kg})$. However, the $b$ value—adsorption affinity—did not show a consistent pattern.

In the Freundlich model, the $\mathrm{R}^{2}$ values for the SCM beads and SP were above 0.96 and 0.90 , respectively. The $K_{\mathrm{F}}$ values were found to be 25,47 , and 44 in the SCM beads $1 / 1 / 0.1$, $1 / 1 / 0.3$, and $1 / 1 / 0.5$, respectively, and the ratio of maghemite was similar at 0.3 or higher. In addition, because the $K_{\mathrm{F}}$ value was approximately 10 times higher for the beads than that for SP, it was found that the adsorption affinity of the beads was higher than that of SP. The $\mathrm{N}$ values were found to be in the range of $0.66-0.71$, indicating nonlinear behavior.

Table 4 also shows the results of fitting with the D-R model, one of the pore volume filling models. Overall, the $\mathrm{R}^{2}$ value was higher than 0.96 . Because As atoms are $119 \mathrm{pm}$ in diameter and exist in the form of arsenate in water, most of the adsorption appears to have occurred in the pores and surfaces of the beads with pore sizes of approximately $20 \mathrm{~nm}$ or more. The $q_{\mathrm{mD}}$ values of beads $1 / 1 / 0.1,1 / 1 / 0.3$, and $1 / 1 / 0.5$ were $28.07,47.22$, and $44.30 \mathrm{mmol} / \mathrm{kg}$, respectively, and the $q_{\mathrm{mD}}$ values of beads $1 / 1 / 0.3$ and $1 / 1 / 0.5$ were similar. This value was approximately 25 times higher than the $1.883 \mathrm{mmol} / \mathrm{kg}$ measured for SP. Comparing $q_{\mathrm{mD}}$ in the D-R model and $q_{\mathrm{mL}}$ in the Langmuir model, $q_{\mathrm{mD}}$ was smaller than $q_{\mathrm{mL}}$. However, the $E$ values are all less than $8 \mathrm{~kJ} / \mathrm{mol}$, indicating that physical adsorption had occurred.

In this study, the dual mode (DM) model, which is a model combining the Langmuir model and the linear model, was also applied to analyze whether monolayer or multi-layer adsorption occurred. Table 4 shows an $\mathrm{R}^{2}$.value of 0.97 or higher for the DM model, which was the same as that for the Langmuir model. The $q_{\mathrm{mDM}}$ value of the DM model and the $q_{\mathrm{mL}}$ value of the Langmuir model were very similar, and the $K_{\mathrm{pDM}}$ value was very low (less than 0.049), indicating that the monolayer adsorption was dominant. 


\subsection{Adsorption Characteristics of Pb onto the Beads}

Figure 5 shows the adsorption isotherms of $\mathrm{Pb}$ onto the SCM beads $(1 / 1 / 0.1,1 / 1 / 0.3$, and $1 / 1 / 0.5$ ) and SP and the fitting for each model (the Langmuir, Freundlich, D-R, and $\mathrm{DM}$ models are shown in Figure $4 \mathrm{a}-\mathrm{d}$, respectively). The lowest $\mathrm{Pb}$ adsorption occurred in bead 1/1/0.1, and the highest adsorption amount occurred in bead 1/1/0.5. The $\mathrm{Pb}$ concentration $\left(q_{\mathrm{e}}\right)$ adsorbed onto the beads significantly increased compared with that adsorbed onto SP and increased with the maghemite ratio in the beads $(1 / 1 / 0.5>1 / 1 / 0.3$ $>1 / 1 / 0.1$ ). Table 5 shows the parameters derived from the regression analyses of the adsorption isotherm models. The $\mathrm{R}^{2}$ values for all model fitting results were greater than 0.618 in bead $1 / 1 / 0.3$. The $\mathrm{R}^{2}$ value of the DM model was the highest of all the models.
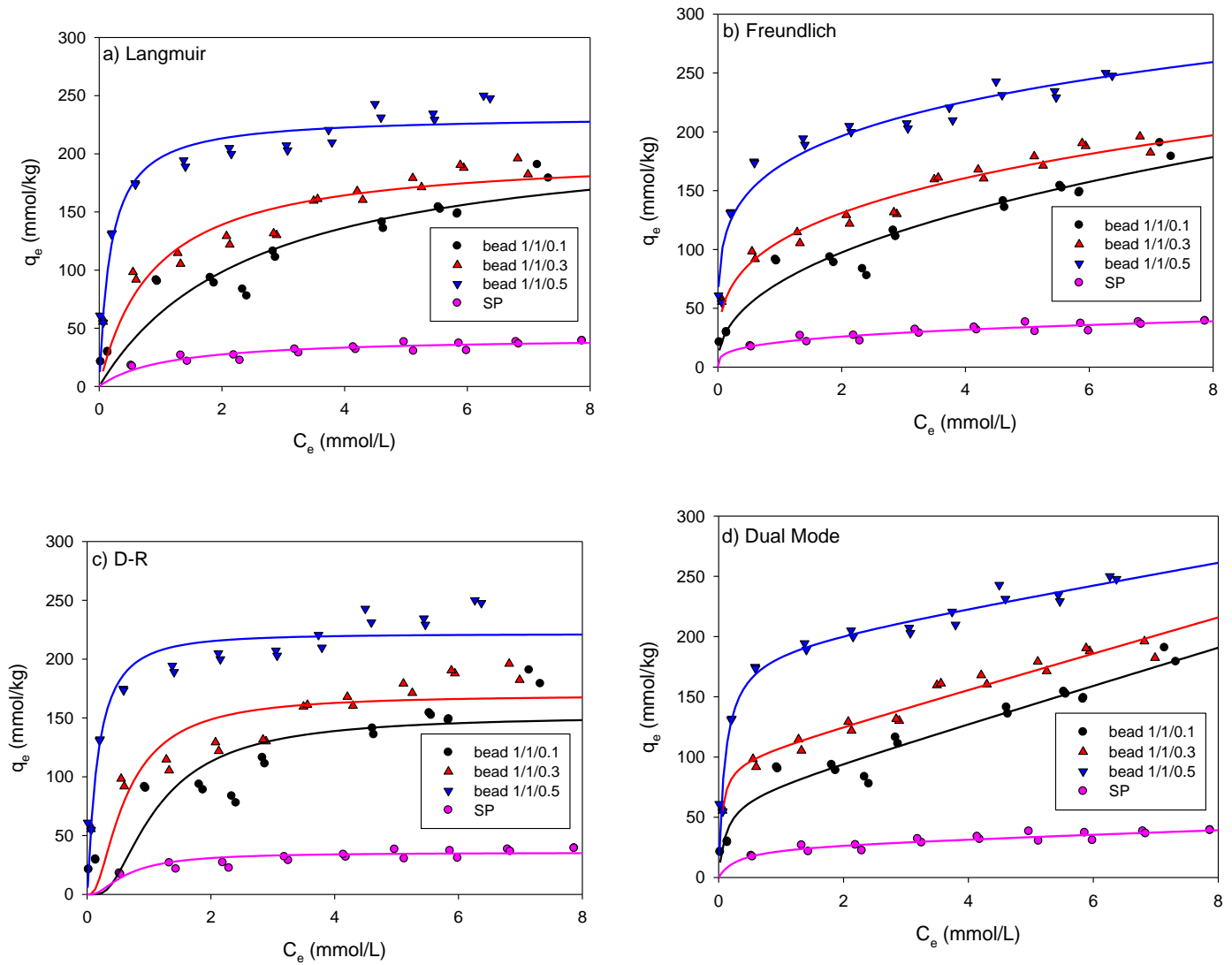

Figure 5. Nonlinear fitting of the (a) Langmuir; (b) Freundlich; (c) D-R; and (d) the dual mode models for Pb adsorption onto the beads and SP.

In the Langmuir model, the maximum adsorption capacity $\left(q_{\mathrm{mL}}\right)$ was $222.2,200.8$ and $232.8 \mathrm{mmol} / \mathrm{kg}$ for beads $1 / 1 / 0.1,1 / 1 / 0.3$, and $1 / 1 / 0.5$, respectively, showing similar results regardless of the ratio. Comparing the $q_{\mathrm{mL}}$ values with that of SPs $(41.8 \mathrm{mmol} / \mathrm{kg})$, those of bead 1/1/0.1 increased by 5.3 times, bead $1 / 1 / 0.3$ increased by 4.8 times, and bead $1 / 1 / 0.5$ increased by 5.6 times. The adsorption affinity, $b$, also increased with the maghemite content. The $\mathrm{R}^{2}$ for the Langmuir model was in the range of 0.797-0.909. This makes it difficult to conclude whether the adsorption of $\mathrm{Pb}$ was a monolayer adsorption.

In Table 5, the Freundlich model showed high $\mathrm{R}^{2}$ values of over 0.93 , which are higher than those of the Langmuir model, indicating the multi-layer adsorption of $\mathrm{Pb}$ onto the beads rather than monolayer adsorption. In addition, the $\mathrm{K}_{\mathrm{F}}$ value - the affinity of the adsorption-increased with the SCM ratio from bead $1 / 1 / 0.1$ to bead $1 / 1 / 0.5$. The $\mathrm{N}$ value was in the range of $0.20-0.44$, showing nonlinear adsorption. 
Table 5. Comparison of the isotherm model parameters for $\mathrm{Pb}$.

\begin{tabular}{|c|c|c|c|c|c|}
\hline \multirow{2}{*}{ Model } & \multirow{2}{*}{ Parameter } & \multicolumn{3}{|c|}{ SCM Beads } & \multirow{2}{*}{ SP } \\
\hline & & $1 / 1 / 0.1$ & $1 / 1 / 0.3$ & 1/1/0.5 & \\
\hline \multirow{5}{*}{ Langmuir } & $q_{\mathrm{mL}}(\mathrm{mmol} / \mathrm{kg})$ & 222.2 & 200.8 & 232.8 & 41.88 \\
\hline & $\mathrm{b}(\mathrm{L} / \mathrm{mmol})$ & 0.398 & 1.126 & 5.452 & 1.037 \\
\hline & $\mathrm{R}^{2}$ & 0.885 & 0.797 & 0.909 & 0.805 \\
\hline & SSE & 5900 & 7042 & 5421 & 197.8 \\
\hline & $\mathrm{R}_{\mathrm{L}}$ & 0.011 & 0.004 & 0.001 & 0.023 \\
\hline \multirow{4}{*}{ Freundlich } & $K_{\mathrm{F}}\left(\mathrm{mmol}^{1-\mathrm{N}} \mathrm{L}^{\mathrm{N}} / \mathrm{kg}\right)$ & 72.00 & 106.8 & 170.9 & 21.71 \\
\hline & $N(-)$ & 0.437 & 0.295 & 0.201 & 0.281 \\
\hline & $\mathrm{R}^{2}$ & 0.944 & 0.960 & 0.936 & 0.856 \\
\hline & SSE & 2854 & 1386 & 3806 & 146.6 \\
\hline \multirow{5}{*}{ D-R } & $q_{\mathrm{mD}}(\mathrm{mmol} / \mathrm{kg})$ & 151.9 & 169.3 & 221.4 & 35.86 \\
\hline & $\beta\left(\mathrm{mol}^{2} / \mathrm{kJ}^{2}\right), \times 10^{-2}$ & 29.40 & 12.90 & 2.831 & 13.10 \\
\hline & $E(\mathrm{~kJ} / \mathrm{mol})$ & 1.304 & 1.971 & 4.206 & 1.953 \\
\hline & $\mathrm{R}^{2}$ & 0.760 & 0.618 & 0.874 & 0.678 \\
\hline & SSE & 12,228 & 13,245 & 7476 & 326.7 \\
\hline \multirow{5}{*}{$\mathrm{DM}$} & $K_{\mathrm{pDM}}(\mathrm{L} / \mathrm{kg})$ & 15.70 & 14.94 & 9.108 & $4.62 \times 10^{-6}$ \\
\hline & $q_{\mathrm{mDM}}(\mathrm{mmol} / \mathrm{kg})$ & 66.04 & 96.91 & 190.7 & 50.35 \\
\hline & $b_{\mathrm{DM}}(\mathrm{L} / \mathrm{mmol})$ & 9.069 & 21.06 & 10.08 & 0.464 \\
\hline & $\mathrm{R}^{2}$ & 0.958 & 0.969 & 0.950 & 0.679 \\
\hline & SSE & 2151 & 1086 & 2993 & 325.7 \\
\hline
\end{tabular}

The $\mathrm{Pb}$ adsorption onto the bead was also fitted with the $\mathrm{D}-\mathrm{R}$ model. The $\mathrm{R}^{2}$ values ranged from 0.62 to 0.87 , indicating relatively low accuracy. The $\mathrm{q}_{\mathrm{mD}}$ values for beads $1 / 1 / 0.1,1 / 1 / 0.3$, and $1 / 1 / 0.5$ were $151.9,169.3$, and $221.4 \mathrm{mmol} / \mathrm{kg}$, respectively, and increased in proportion to the maghemite dose. The $\mathrm{E}$ values were all $8 \mathrm{~kJ} / \mathrm{mol}$ or less, indicating that physical adsorption occurred.

The DM model can analyze the dominant model between the physical multi-layer adsorptions and the monolayer adsorption. Its $\mathrm{R}^{2}$ values were the highest (all above 0.950 ) of the models. This is because the beads have various adsorption sites composed of a composite component with a difference in adsorption affinity between the maghemite and $\mathrm{SP}$. Unlike As adsorption, the $\mathrm{K}_{\mathrm{pDM}}$ values in the model for $\mathrm{Pb}$ adsorption were high at $15.7,14.9$, and 9.1 for beads $1 / 1 / 0.1,1 / 1 / 0.3$, and $1 / 1 / 0.5$, respectively, showing a decrease with increasing maghemite content. Conversely, the $\mathrm{K}_{\mathrm{pDM}}$ value for the $\mathrm{Pb}$ adsorption onto SP was nearly 0 . In addition, the $\mathrm{q}_{\mathrm{mDM}}$ value was $66.0,96.9$, and $190.7 \mathrm{mmol} / \mathrm{kg}$ for beads $1 / 1 / 0.1,1 / 1 / 0.3$ and $1 / 1 / 0.5$, respectively, increasing in proportion to the maghemite content.

\section{4. $p H$ Effect for the Maximum Adsorption Capacities of As and Pb onto the Beads and SP}

Figure 6 shows the $\mathrm{pH}$ effect of $\mathrm{As}$ and $\mathrm{Pb}$ adsorption onto the beads, indicating that both $\mathrm{As}$ and $\mathrm{Pb}$ adsorption increased with $\mathrm{pH}$. To better observe the effect of $\mathrm{pH}$ on $\mathrm{As}$ and $\mathrm{Pb}$ adsorption, the adsorption experiment was performed at a low concentration and interpreted using the Freundlich model. The magnitude of the $\mathrm{K}_{\mathrm{F}}$ value in the model is related to the adsorption affinity. As shown in Figure 6 and Table 6, the $\mathrm{K}_{\mathrm{F}}$ values increased with increasing $\mathrm{pH}$, with 102.6 (at pH 7.0) > 100.3 (at pH 5.5) > 53.3 (at $\mathrm{pH} 4.0$ ) for As adsorption and 512.7 (at pH 7.0) > 440.7 (at pH 5.5) > 394.4 (at pH 4.0) for Pb adsorption, indicating that the $\mathrm{Pb}$ adsorption affinity was higher overall than the As adsorption affinity. 

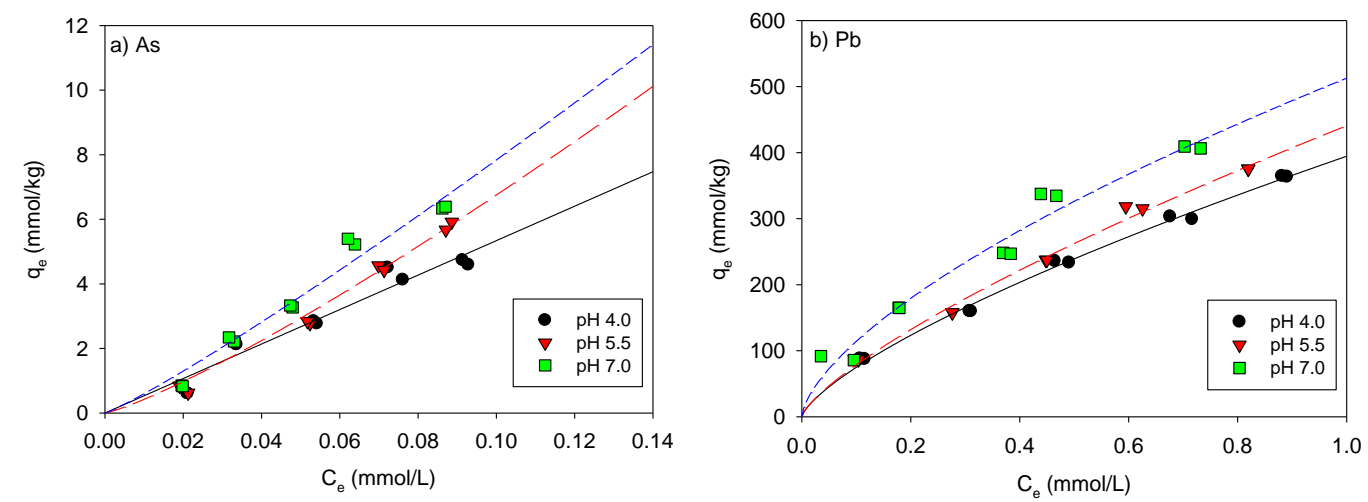

Figure 6. Effect of $\mathrm{pH}$ on the (a) As and (b) Pb adsorption fitted using the Freundlich model.

Table 6. Comparison of the $K_{\mathrm{F}}$ values in the Freundlich model.

\begin{tabular}{ccc}
\hline \multirow{2}{*}{$\mathbf{p H}$} & \multicolumn{3}{c}{$\mathbf{K}_{\mathbf{F}}\left(\mathbf{m m o l}^{\mathbf{1}-\mathbf{N}} \mathbf{L}^{\mathbf{N}} / \mathbf{k g}\right)$} \\
\cline { 2 - 3 } & $\mathbf{A s}$ & $\mathbf{P b}$ \\
\hline 4.0 & 53.31 & 394.4 \\
5.5 & 100.3 & 440.7 \\
7.0 & 102.6 & 512.7 \\
\hline
\end{tabular}

\subsection{Temperature Effect on the Adsorption of As and Pb onto the Beads and SP}

A thermodynamics analysis was conducted for the adsorption of $\mathrm{As}$ and $\mathrm{Pb}$ onto the beads to estimate whether the reaction occurred spontaneously. The partition coefficient $K_{p}$ in the linear model was used as a thermodynamic parameter related to the Gibb's free energy change, $\Delta G^{0}(\mathrm{~kJ} / \mathrm{mol})$ during adsorption. The changes in the enthalpy, $\Delta H^{0}(\mathrm{~kJ} / \mathrm{mol})$, and the entropy, $\Delta S^{0}(\mathrm{~J} / \mathrm{mol} / \mathrm{K})$, were also calculated using the following equations:

$$
\begin{aligned}
\Delta G^{0} & =-R T \ln K_{p} \\
\ln K_{p} & =\frac{\Delta S^{0}}{R}-\frac{\Delta H^{0}}{R T}
\end{aligned}
$$

where $R$ is the gas constant $(8.314 \mathrm{~J} / \mathrm{K} / \mathrm{mol}), \mathrm{T}$ is the absolute temperature in Kelvin, and $K_{p}$ is the partitional coefficient.

The effect of temperature on the adsorption of As and $\mathrm{Pb}$ onto the SCM beads is shown in Figure 7 and the thermodynamic parameters are presented in Table 7. Overall, the $\ln \left(\mathrm{K}_{p}\right)$ values for $\mathrm{As}$ and $\mathrm{Pb}$ adsorption increased as the temperature increased from 293 to $313 \mathrm{~K}$. As shown in Table 7 , the $\Delta \mathrm{H}^{\circ}$ value for As is higher than that for $\mathrm{Pb}$, indicating that the As adsorption is a more endothermic reaction than the $\mathrm{Pb}$ adsorption. The $\Delta \mathrm{S}^{\circ}$ values for $\mathrm{As}$ and $\mathrm{Pb}$ are 133.1 and 79.16, respectively. The positive values indicate that the adsorption process was accompanied by structural changes in the adsorbent and adsorbate [20]. The negative values of the change in the free energy $\left(\Delta G^{\circ}\right)$ indicated that the adsorption isotherms of both $\mathrm{As}$ and $\mathrm{Pb}$ were spontaneous in nature and that the value for $\mathrm{Pb}$ was lower than that for As, causing more active $\mathrm{Pb}$ adsorption than As adsorption onto the beads. However, the changes in the enthalpy $\left(\Delta \mathrm{H}^{\circ}\right)$ were negative, indicating an endothermic reaction. Overall, the reaction ratios of these adsorptions increased with temperature. 

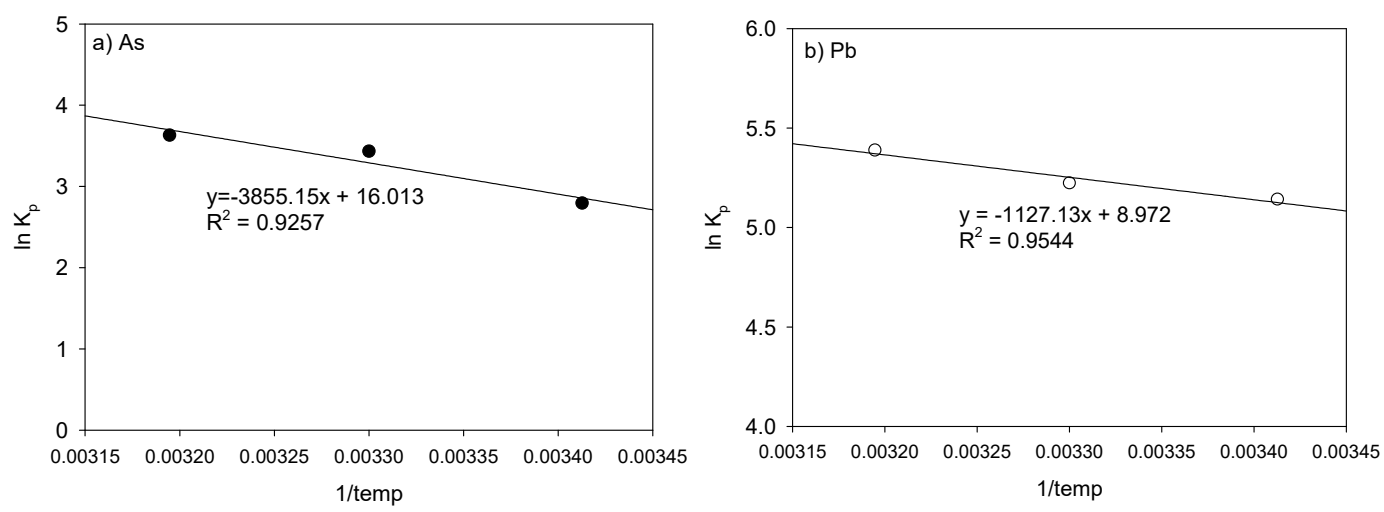

Figure 7. Temperature effects on (a) As and (b) $\mathrm{Pb}$ adsorption.

Table 7. Thermodynamic parameters for the adsorption of As and $\mathrm{Pb}$ onto the beads.

\begin{tabular}{|c|c|c|c|c|c|}
\hline & \multirow{2}{*}{$\begin{array}{c}\Delta H \\
(\mathrm{~kJ} / \mathrm{mol})\end{array}$} & \multirow{2}{*}{$\begin{array}{c}\Delta \mathrm{S} \\
\left(\mathrm{kJ} / \mathrm{mol} / \mathrm{K}, \times 10^{3}\right)\end{array}$} & \multicolumn{3}{|c|}{$\Delta \mathrm{G}(\mathrm{kJ} / \mathrm{mol})$} \\
\hline & & & $293 \mathrm{~K}$ & $303 \mathrm{~K}$ & $313 \mathrm{~K}$ \\
\hline As & 32.05 & 133.1 & -6.955 & -8.287 & -9.618 \\
\hline $\mathrm{Pb}$ & 8.457 & 79.16 & -14.74 & -15.53 & -16.32 \\
\hline
\end{tabular}

\section{Conclusions}

SCM composite beads were prepared with different mass ratios of $1 / 1 / 0.1,1 / 1 / 0.3$, and $1 / 1 / 0.5$ of SP/chitosan/maghemite, respectively, for the adsorption of $\mathrm{As}$ and $\mathrm{Pb}$. The composite beads had maximum uptakes of 1.83 and $50.0 \mathrm{mmol} / \mathrm{kg}$ for $\mathrm{As}$ and $\mathrm{Pb}$, respectively. The optimum mass ratio of SP, chitosan, and maghemite in the bead for the maximum adsorption capacity was $1 / 1 / 0.5$. The experimental data were analyzed using several adsorption isotherm models. From the results of the model fitting, the beads had multiple adsorption sites with different affinities resulting from the inclusion of maghemite compared with SP and the DM model was the best model to describe these differences. The adsorption also depended on the $\mathrm{pH}$ and temperature. The thermodynamic study indicated that the adsorption reactions of $\mathrm{As}$ and $\mathrm{Pb}$ onto the beads are endothermic and spontaneous resulting from the large increase in the entropy change. In conclusion, beads could be used as good effective adsorbents for $\mathrm{As}$ and $\mathrm{Pb}$ removal from water resources, including rivers and groundwater.

Author Contributions: Conceptualization, K.J., S.O.; methodology, H.P., J.W., S.O.; validation, S.O.; formal analysis, J.P.; data curation, H.P., J.W., K.J.; writing-original draft preparation, S.O.; writingreview and editing, S.O.; supervision, S.O.; funding acquisition, K.J., S.O. All authors have read and agreed to the published version of the manuscript.

Funding: This research was funded by Korea Research Foundation (NRF-2018R1D1A1B07049783).

Institutional Review Board Statement: Not applicable.

Informed Consent Statement: Not applicable.

Acknowledgments: The authors are grateful to Kyungpook National University for supporting this research.

Conflicts of Interest: The authors declare no conflict of interest.

\section{References}

1. Shankar, S.; Shanker, U. Shikha Arsenic Contamination of Groundwater: A Review of Sources, Prevalence, Health Risks, and Strategies for Mitigation. Sci. World J. 2014, 2014, 1-18. [CrossRef]

2. Postma, D.; Mai, N.T.H.; Lan, V.M.; Trang, P.T.K.; Sø, H.U.; Nhan, P.Q.; Larsen, F.; Viet, P.H.; Jakobsen, R. Fate of Arsenic during Red River Water Infiltration into Aquifers beneath Hanoi, Vietnam. Environ. Sci. Technol. 2016, 51, 838-845. [CrossRef] 
3. Mukherjee, A.; Sengupta, M.K.; Hossain, M.A.; Ahamed, S.; Das, B.; Nayak, B.; Lodh, D.; Rahman, M.M.; Chakraborti, D. Arsenic contamination in groundwater: A global perspective with emphasis on the Asian scenario. J. Health Popul. Nutr. 2006, $24,142-163$.

4. Jiang, J.Q.; Ashekuzzaman, S.M.; Jiang, A.; Sharifuzzaman, S.M.; Chowdhury, S.R. Arsenic Contaminated Groundwater and Its Treatment Options in Bangladesh. Int. J. Environ. Res. Public Health 2012, 10, 18-46. [CrossRef]

5. Clausen, J.L.; Bostick, B.; Korte, N. Migration of lead in surface water, pore water, and groundwater with a focus on firing ranges. Crit. Rev. Environ. Sci. Technol. 2011, 41, 1397-1448. [CrossRef]

6. Aredes, S.; Klein, B.; Pawlik, M. The removal of arsenic from water using natural iron oxide minerals. J. Clean. Prod. 2013, 60, 71-76. [CrossRef]

7. Cantu, J.; Gonzalez, L.E.; Goodship, J.; Contreras, M.; Joseph, M.; Garza, C.; Eubanks, T.M.; Parsons, J.G. Removal of arsenic from water using synthetic $\mathrm{Fe}_{7} \mathrm{~S}_{8}$ nanoparticles. Chem. Eng. J. 2016, 290, 428-437. [CrossRef]

8. Matchida, M.; Kikuchi, Y.; Aikawa, M.; Tatsumoto, H. Kinetics of adsorption and desorption of Pb(II) in aqueous solution on activated carbon by two-site adsorption model. Colloids Surf. A Physicochem. Eng. Asp. 2004, 240, 179-186. [CrossRef]

9. Ghosh, M.K.; Poinern, G.E.J.; Issa, T.B.; Singh, P. Arsenic adsorption on goethite nanoparticles produced through hydrazine sulfate assisted synthesis method. Korean J. Chem. Eng. 2012, 29, 95-102. [CrossRef]

10. Guo, H.; Ren, Y.; Liu, Q.; Zhao, K.; Li, Y. Enhancement of arsenic adsorption during mineral transformation from siderite to goethite: Mechanism and application. Environ. Sci. Technol. 2013, 47, 1009-1016. [CrossRef]

11. Mamindy-Pajany, Y.; Hurel, C.; Marmier, N.; Roméo, M. Arsenic (V) adsorption from aqueous solution onto goethite, hematite, magnetite and zero-valent iron: Effects of $\mathrm{pH}$, concentration and reversibility. Desalination 2011, 281, 93-99. [CrossRef]

12. Siddiqui, S.I.; Chaudhry, S.A. Iron oxide and its modified forms as an adsorbent for arsenic removal: A comprehensive recent advancement. Process. Saf. Environ. Prot. 2017, 111, 592-626. [CrossRef]

13. Tuutijärvi, T.; Lu, J.; Sillanpää, M.; Chen, G. As(V) adsorption on maghemite nanoparticles. J. Hazard. Mater. 2009, 166, 1415-1420. [CrossRef]

14. Raven, K.P.; Jain, A.; Loeppert, R.H. Arsenite and Arsenate Adsorption on Ferrihydrite: Kinetics, Equilibrium, and Adsorption Envelopes. Environ. Sci. Technol. 1998, 32, 344-349. [CrossRef]

15. Liang, Y.; Min, X.; Chai, L.; Wang, M.; Liyang, W.; Pan, Q.; Okido, M. Stabilization of arsenic sludge with mechanochemically modified zero valent iron. Chemosphere 2017, 168, 1142-1151. [CrossRef] [PubMed]

16. Luong, T.V.; Kurz, E.E.C.; Hellriegel, U.; Luu, T.L.; Hoinkis, J.; Bundschuh, J. Iron-based subsurface arsenic removal technologies by aeration: A review of the current state and future prospects. Water Res. 2018, 133, 110-122. [CrossRef]

17. Lee, J.C.; Kim, E.J.; Kim, H.W.; Baek, K. Oxalate-based remediation of arsenic bound to amorphous Fe and Al hydrous oxides in soil. Geoderma 2016, 270, 76-82. [CrossRef]

18. Pintor, A.M.; Vieira, B.R.; Santos, S.C.; Boaventura, R.; Botelho, C.M. Arsenate and arsenite adsorption onto iron-coated cork granulates. Sci. Total. Environ. 2018, 642, 1075-1089. [CrossRef]

19. Niazi, N.K.; Burton, E.D. Arsenic sorption to nanoparticulate mackinawite (FeS): An examination of phosphate competition. Environ. Pollut. 2016, 218, 111-117. [CrossRef]

20. Adhikari, T.; Singh, M.V. Sorption characteristics of lead and cadmium in some soils of India. Geoderma 2003, 114, 81-92. [CrossRef]

21. Unuabonah, E.I.; Adebowale, K.O. Optimization of kinetic data for two-stage batch adsorption of $\mathrm{Pb}(\mathrm{II})$ ions onto tripolyphosphate-modified kaolinite clay. J. Chem. Technol. Biotechnol. 2009, 84, 1726-1735. [CrossRef]

22. Polcaro, A.M.; Mascia, M.; Palmas, S.; Vacca, A.; Tola, G. Competitive Sorption of Heavy Metal Ions by Soils. Environ. Eng. Sci. 2003, 20, 607-616. [CrossRef]

23. Trancoso, M.A.; Santos, M.M.; Gonçalves, M.L.S. Lead sorption to selected Portuguese soils. Eur. J. Soil Sci. 2006, 58, 854-863. [CrossRef]

24. Lee, D.H.; Moon, H. Adsorption equilibrium of heavy metals on natural zeolites. Korean J. Chem. Eng. 2001, 18, 247-256. [CrossRef]

25. Kadirvelu, K.; Goel, J.; Rajagopal, C. Sorption of lead, mercury and cadmium ions in multi-component system using carbon aerogel as adsorbent. J. Hazard. Mater. 2008, 153, 502-507. [CrossRef]

26. Liu, C.; Huang, P. Kinetics of lead adsorption by iron oxides formed under the influence of citrate. Geochim. Cosmochim. Acta 2003, 67, 1045-1054. [CrossRef]

27. Xu, P.; Zeng, G.M.; Huang, D.L.; Lai, C.; Zhao, M.H.; Wei, Z.; Li, N.J.; Huang, C.; Xie, G.X. Adsorption of Pb(II) by iron oxide nanoparticles immobilized Phanerochaete chrysosporium: Equilibrium, kinetic, thermodynamic and mechanisms analysis. Chem. Eng. J. 2012, 203, 423-431. [CrossRef]

28. Mahmond, Z.H.; Abdalkareem, A.A. Removal of $\mathrm{Pb}^{2+}$ ions from water by magnetic iron oxide nanoparticles that prepared via ECD. Eur. J. Sci. Res. 2017, 145, 354-365.

29. Xia, Z.; Baird, L.; Zimmerman, N.; Yeagar, M. Heavy metal ion removal by thiol functionalized aluminum oxide hydroxide nanowhiskers. Appl. Surface Sci. 2017, 416, 565-573. [CrossRef]

30. Fakour, H.; Pan, Y.F.; Lin, T.F. Effect of Humic Acid on Arsenic Adsorption and Pore Blockage on Iron-Based Adsorbent. Water Air Soil Pollut. 2015, 226, 1-16. [CrossRef]

31. Cho, D.W.; Jeon, B.H.; Chon, C.M.; Schwartz, F.W.; Jeong, Y.; Song, H. Magnetic chitosan composite for adsorption of cationic and anionic dyes in aqueous solution. J. Ind. Eng. Chem. 2015, 28, 60-66. [CrossRef] 
32. Podder, M.S.; Majumder, C.B. Application of granular activated carbon/ $\mathrm{MnFe}_{2} \mathrm{O}_{4}$ composite immobilized on C. glutamicum MTCC 2745 to remove As(III) and As(V): Kinetic, mechanistic and thermodynamic studies. Spectrochim. Acta Part A Mol. Biomol. Spectrosc. 2016, 153, 298-314. [CrossRef] [PubMed]

33. Obeid, L.; Bée, A.; Talbot, D.; Jaafar, S.B.; Dupuis, V.; Abramson, S.; Cabuil, V.; Welschbillig, M. Chitosan/maghemite composite: A magsorbent for the adsorption of methyl orange. J. Colloid Interface Sci. 2013, 410, 52-58. [CrossRef] [PubMed]

34. Bée, A.; Obeid, L.; Mbolantenaina, R.; Welschbillig, M.; Talbot, D. Magnetic chitosan/clay beads: A magsorbent for the removal of cationic dye from water. J. Magn. Magn. Mater. 2017, 421, 59-64. [CrossRef]

35. Sureshkumar, M.K.; Das, D.; Mallia, M.B.; Gupta, P.C. Adsorption of uranium from aqueous solution using chitosantripolyphosphate (CTPP) beads. J. Hazard. Mater. 2010, 184, 65-72. [CrossRef]

36. Ngah, W.W.; Fatinathan, S. Adsorption characterization of $\mathrm{Ph}(\mathrm{II})$ and $\mathrm{Cu}(\mathrm{II})$ ions onto chitosan-tripolyphosphate beads: Kinetic, equilibrium and thermodynamic studies. J. Environ. Manag. 2010, 91, 958-969. [CrossRef]

37. Mahzuz, H.M.A.; Ahmed, A.A.M.; Yusuf, M.A. Use of stone powder in concrete and mortar as an alternative of sand. Afr. J. Environ. Sci. Technol. 2011, 5, 381-388.

38. Jung, K.; Oh, S.; Bak, H.; Song, G.H.; Kim, H.T. Adsorption of Arsenic and Lead onto Stone Powder and Chitosan-Coated Stone Powder. Processes 2019, 7, 599. [CrossRef]

39. Massart, R. Preparation of aqueous magnetic liquids in alkaline and acidic media. IEEE Trans. Magn. 1981, 17, 1247-1248. [CrossRef]

40. Hu, Q.; Zhang, Z. Application of Dubinin-Radushkevich isotherm model at the solid/solution interface: A theoretical analysis. J. Mol. Liq. 2019, 277, 646-648. [CrossRef]

41. Xia, G.; Ball, W.P. Adsorption-Partitioning Uptake of Nine Low-Polarity Organic Chemicals on a Natural Sorbent. Environ. Sci. Technol. 1999, 33, 262-269. [CrossRef] 